\title{
Body composition monitoring in children and adolescents: reproducibility and reference values
}

\author{
Annelies Van Eyck ${ }^{1,2} \cdot$ Sofie Eerens ${ }^{2} \cdot$ Dominique Trouet $^{1,2} \cdot$ Eline Lauwers $^{1} \cdot$ Kristien Wouters $^{3,4} \cdot$ Benedicte Y. De \\ Winter $^{1,5}$ • Johanna H. van der Lee ${ }^{6} \cdot$ Koen Van Hoeck $^{2} \cdot$ Kristien J. Ledeganck $^{1,7}$ (D)
}

Received: 9 October 2020 / Revised: 4 January 2021 / Accepted: 7 January 2021 / Published online: 22 January 2021

(C) The Author(s) 2021

\begin{abstract}
There is an increasing need for suitable tools to evaluate body composition in paediatrics. The Body Composition Monitor (BCM) shows promise as a method, but reference values in children are lacking. Twenty children were included and measured twice by 4 different raters to asses inter- and intra-rater reproducibility of the BCM. Reliability was assessed using the BlandAltman method and by calculating intraclass correlation coefficients (ICCs). The intra-rater ICCs were high $(\geq 0.97)$ for all parameters measured by BCM as were the inter-rater ICCs for all parameters $(\geq 0.98)$ except for overhydration $(0.76)$. Consequently, a study was set up in which BCM measurements were performed in 2058 healthy children aged 3-18.5 years. The age- and gender-specific percentile values and reference curves for body composition (BMI, waist circumference, fat mass and lean tissue mass) and fluid status (extracellular and intracellular water and total body water) relative to age were produced using the GAMLSS method for growth curves.

Conclusion: A high reproducibility of BCM measurements was found for fat mass, lean tissue mass, extracellular water and total body water. Reference values for these BCM parameters were calculated in over 2000 children and adolescents aged 3 to 18 years.
\end{abstract}

\section{What is Known:}

- The 4-compartment model is regarded as the 'gold standard' of body composition methods, but is inappropriate for regular follow-up or screening of large groups, because of associated limitations.

- Body Composition Monitor ${ }^{\circledR}$ is an inexpensive field method that has the potential to be an adequate monitoring tool.

What is New:

- Good reproducibility of BCM measurements in children provides evidence to use the device in longitudinal follow-up, multicentre and comparative studies.

- Paediatric reference values relative to age and sex for the various compartments of the body are provided.

Annelies Van Eyck and Sofie Eerens contributed equally to this work.

Koen Van Hoeck and Kristien J. Ledeganck are shared last authors

Communicated by Daniele De Luca

Kristien J. Ledeganck

kristien.ledeganck@uantwerpen.be

Annelies Van Eyck

annelies.vaneyck@uantwerpen.be

Sofie Eerens

sofie_eerens@hotmail.com

Dominique Trouet

dominique.trouet@uza.be

Eline Lauwers

eline.lauwers@uantwerpen.be

\author{
Kristien Wouters \\ kristien.wouters@uza.be \\ Benedicte Y. De Winter \\ benedicte.dewinter@uantwerpen.be \\ Johanna H. van der Lee \\ h.vanderlee@kennisinstituut.nl \\ Koen Van Hoeck \\ koen.vanhoeck@uza.be
}

Extended author information available on the last page of the article 
Keywords Body composition · Children · Adolescents $\cdot$ Reference $\cdot$ Reproducibility $\cdot$ Reliability

$\begin{array}{ll}\text { Abbreviations } \\ \text { ATM } & \text { Adipose tissue mass } \\ \text { ANOVA } & \text { Analysis of variance } \\ \text { BCM } & \text { Body Composition Monitor }{ }^{\circledR} \\ \text { BIS } & \text { Bioimpedance spectroscopy } \\ \text { BMI } & \text { Body mass index } \\ \text { ECW } & \text { Extracellular water } \\ \text { FM } & \text { Fat mass } \\ \text { GAMLSS } & \text { Generalized additive models for location, scale } \\ & \text { and shape } \\ \text { ICC } & \text { Intraclass correlation coefficients } \\ \text { ICW } & \text { Intracellular water } \\ \text { LoA } & \text { Limits of agreement } \\ \text { LTM } & \text { Lean tissue mass } \\ \text { OH } & \text { Overhydration } \\ \text { SDC } & \text { Smallest detectable change } \\ \text { SDS } & \text { Standard deviation score } \\ \text { TBW } & \text { Total body water }\end{array}$

\section{Introduction}

The World Health Organization recognizes childhood obesity as one of the most serious public health challenges of the twentyfirst century [1]. Excessive adipose tissue is associated with significant health consequences later in life, such as cardiovascular diseases, type 2 diabetes mellitus and cancer [1]. Therefore, there is an increasing need for tools suitable in paediatric care to evaluate body composition in both clinical and research settings [2]. In addition, the importance of nutritional assessment is not restricted to children with overweight and obesity, but is also highly relevant in a variety of conditions and chronic diseases. Among others, childhood cancer, chronic inflammatory diseases, chronic kidney disease and cystic fibrosis have all been associated with an altered body composition [3].

Different techniques are available for body composition analysis, ranging from basic anthropometric measurements to densitometry and advanced imaging techniques. Body mass index (BMI) is one of the most simple and widely used methods to identify children and adolescents with excess adiposity and malnutrition, but this measure cannot be used to distinguish fat mass from lean tissue mass [3]. This disadvantage is highly relevant in the paediatric population, since the proportion of fat and lean tissue mass during childhood varies by age, gender, ethnicity and the level of hormonal maturation [4]. The 4-compartment (4C) model is the most accurate in vivo measurement of fat mass and lean tissue mass and as such is regarded as the 'gold standard' of body composition methods [5]. The 4C model, however, is inappropriate for regular follow-up or screening of large groups of patients, because of its associated limitations such as its high cost and it being a time-consuming procedure [6]. In contrast, the Body Composition Monitor ${ }^{\circledR}$ (BCM, Fresenius Medical Care, Germany) is an inexpensive field method that has the potential to be an adequate monitoring tool [7]. The technology uses bioimpedance spectroscopy (BIS) to determine total body water (TBW) and extracellular water (ECW) volume. Using advanced models, three body composition compartments can be derived from these measurements: lean tissue, adipose tissue and excess fluid or 'overhydration' [8]. Parameters of the BCM model have shown good to excellent agreement with the respective gold standard methods in adults [9], but validation studies in children are lacking. To date, only parameters related to the fluid status have been validated in healthy children and children receiving haemodialysis [10]. Initially, the application of the device focused on the evaluation of the fluid status in end-stage renal disease patients. Nevertheless, over the past few years, the BCM is increasingly being used for nutritional assessment as well $[11,12]$. The BCM model has shown potential in various populations in paediatrics, but several barriers still need to be overcome to allow a widespread application of the device in both research and clinical practices. More particularly, knowledge of the reproducibility and appropriate reference values are important to help facilitate the interpretation of longitudinal data and results obtained in different centres. Therefore, the aims of this study were firstly to investigate the inter- and intra-rater reproducibility of the BCM device and secondly to provide gender-specific reference curves for body composition relative to age in children aged 3-18 years using the BCM.

\section{Materials and methods}

\section{Study population}

In this prospective study, children aged 3-18 years were recruited between June 2012 and March 2020 through their respective schools.

The ethics committee of the Antwerp University Hospital approved this study $\left(\mathrm{EC} \mathrm{n}^{\circ} \mathrm{B} 300201939802\right.$ and B300201214619) and informed consent was obtained from the children and their parents or legal guardians.

\section{Study design}

\section{Inter- and intra-rater reproducibility}

Twenty healthy children were recruited voluntarily through advertisement in the staff of the Antwerp University Hospital 
and measurements were performed at the Antwerp University Hospital. Eight investigators from eight different paediatric nephrology centres performed the measurements. A short training was given at the start, including a 15-min teaching DVD with general instructions. Each measurement lasted approximately $5 \mathrm{~min}$. Each child was measured twice by the same investigator with a time interval of $30 \mathrm{~min}$ and was measured by the four different investigators in a time frame of four hours. Data of measurements were not visible to other raters. Between measurements, each child was allowed to play for $30 \mathrm{~min}$. During the $4 \mathrm{~h}$ of assessment, the children were having free drinks and food. The food and fluid intake was not registered.

\section{Reference values}

A total of 2058 children were recruited in 15 Belgian schools (see acknowledgments). School management approved the presence of the research team and the study protocol beforehand. Measurements were performed at the school and children were measured consecutively during the school day.

\section{Anthropometry}

Height was measured to the nearest millimetre using a standing stadiometer and weight was recorded to the nearest $0.1 \mathrm{~kg}$ using an electronic scale (M302000-02 ADE, Hamburg, Germany). Body mass index (BMI) was calculated as weight (in kilogrammes) over height (in meters) squared and was further analysed as standard deviation scores (SDS), using the Flemish growth study as a reference population [13]. The waist circumference was measured as the smallest circumference between the lowest ribs and highest hip comb approximately $1 \mathrm{~cm}$ above the umbilicus.

\section{Bioimpedance spectroscopy}

A BCM measurement was performed in all children (Fresenius Medical Care, St. Wendel, Germany) with the child lying supine.

Electrodes were attached following the wrist-ankle approach, in a tetrapolar arrangement. Four electrodes are used per measurement. Two electrodes are placed on the hand: one on the wrist and the second on the dorsal side of the metacarpalia, close to the phalanges. The other two electrodes are placed on the foot: one on the ankle and the second on the dorsal side of the metatarsals, close to the phalanges of the toes. To guarantee a good contact of the electrodes with the skin, degreasing with diethylether was performed before the placement of the electrodes. Age, gender, height, weight and blood pressure were registered in the device before starting the measurement. If the quality calculated by BCM was $<60 \%$, the measurement was repeated and only good quality measurements were used.
All guidelines for the use of the BCM were followed: nonelectrical bed, no cell phones and no electrical devices within $1 \mathrm{~m}$ of the device.

The parameters of interest were extracellular water (ECW), intracellular water (ICW) and total body water (TBW) in litres and fat (FM) and lean tissue mass (LTM) in kilogrammes. Overhydration $(\mathrm{OH})$ (in litres) is calculated from the distribution of water in LTM and adipose tissue mass (ATM).

\section{Statistical analysis}

\section{Inter- and intra-rater variability}

The reproducibility was assessed by calculating the intraclass correlation coefficients (ICCs) according to the following formulas [14] based on the values of the variance components that are derived from analysis of variance (ANOVA) [15]:

For intra-rater reproducibility:

$\mathrm{ICC}=\left[\operatorname{Var}_{\mathrm{c}}+\operatorname{Var}_{\mathrm{C}^{*} \mathrm{r}}\right] /\left[\operatorname{Var}_{\mathrm{c}}+\operatorname{Var}_{\mathrm{m}}+\operatorname{Var}_{\mathrm{C}^{*} \mathrm{r}}+\operatorname{Var}_{\mathrm{c}^{* m}}+\operatorname{Var}_{\mathrm{m}^{*} \mathrm{r}}+\operatorname{Var}^{\mathrm{E}}\right]$

And for inter-rater reproducibility:

$\mathrm{ICC}=\left[\operatorname{Var}_{\mathrm{C}}+\operatorname{Var}_{\mathrm{C} * \mathrm{~m}}\right] /\left[\operatorname{Var}_{\mathrm{C}}+\operatorname{Var}_{\mathrm{r}}+\operatorname{Var}_{\mathrm{C}{ }_{\mathrm{r}}}+\operatorname{Var}_{\mathrm{C} * \mathrm{~m}}+\operatorname{Var}_{\mathrm{m} * \mathrm{r}}+\operatorname{Var}_{\mathrm{E}}\right]$

with $\operatorname{Var}_{c}$ as the children-induced variance, $\operatorname{Var}_{\mathrm{r}}$ as the raterinduced variance and $\mathrm{Var}_{\mathrm{m}}$ as the measurement-induced variance. $\operatorname{Var}_{\mathrm{c} * \mathrm{r}}, \operatorname{Var}_{\mathrm{c} * \mathrm{~m}}$ and $\operatorname{Var}_{\mathrm{m} *_{\mathrm{r}}}$ are the variances caused by the interaction of children, raters and measurements, and $\operatorname{Var}_{\mathrm{E}}$ is the residual or error variance. The ICC ranges from 0 to 1 , with higher values indicating a higher reproducibility.

The magnitude of the measurement error expressed as smallest detectable change (SDC) was calculated as SDC = $1.96 * \sqrt{2} * \sqrt{ }$ VarE and denotes the smallest change within an individual that can be interpreted as 'real' change, not due to measurement error [16].

Bland-Altman plots were used to further visualize and quantify inter- and intra-rater reproducibility. For the intrarater variability, the differences between 2 measurements per combination of child and investigator were plotted against the means of these 2 measurements [17]. Bias and limits of agreement (LoA) (calculated as the mean difference \pm 1.96 times the standard deviation of the differences per patient) were calculated. These limits indicate how large the difference between two measurements of the same rater on the same child can be. For the inter-rater variability, we look at modified Bland-Altman plots for multiple observers [18]. The difference between each observation and the mean of all observations for one child are plotted against the overall mean for that child, using a different symbol for each rater. The limits of agreement now represent how different ratings of an individual observer are, compared to the mean of all observers.

Sample size calculation of the reproducibility study was based on the accuracy of the ICC. With an anticipated ICC 
of 0.85 and a desired precision of 0.1 , we needed to include 20 patients in a design with 4 raters [19]. Precision is hereby defined as half width of the $95 \%$ confidence interval.

\section{Reference values}

Gender-specific smoothed centile curves were computed for body composition (BMI, waist circumference, FM, LTM) and fluid status (ECW, ICW and TBW) using generalized additive models for location, scale and shape (GAMLSS) [20]. The GAMLSS method is an extension of the LMS method for modelling growth curves [21] and involves two processes: (i) fitting a parametric distribution for the response variable for each age and (ii) smoothing the distribution across age for each parameter of the selected parametric distribution function. The two processes are estimated simultaneously by iterative penalized likelihood maximization using the R package 'gamlss' (http://www.gamlss.org/) [22] in R version 3.6.3 (R Foundation for Statistical Computing, Vienna, Austria, http:// cran.us.r-project.org/). Within the GAMLSS framework, we assessed three distribution families: Box-Cox Cole and Green (BCCG), Box-Cox power exponential (BCPE) and Box-Cox $t$ (BCT). These distribution families allow the modelling of the location (mu), variance (sigma), skewness (nu) and depending on the distribution kurtosis (tau). Goodness of fit of the models was assessed using worm plots, Q-statistic and visual inspection of the centile curves. Model selection was based on the generalized Akaike information criterion (G-AIC) and goodness of fit. Final GAMLSS model parameters were used to produce centile tables and curves for boys and girls separately.

Precision of the centile curves is estimated based on bootstrap simulations in analogy with Cole et al. [23] In 1000 bootstrap runs, the standard error for the different percentiles is computed relative to the age-dependent standard deviation.

\section{Results}

\section{Inter- and intra-rater variability}

A total of 20 children were included with a median age of 9 (3-17) years, a median weight of $30(15-65) \mathrm{kg}$, and a median height of $1.35(0.99-1.77) \mathrm{m}$. The median BMI was 16.6 (13.9-24.6) $\mathrm{kg} / \mathrm{m}^{2}$, which corresponds to a BMI SDS of $0.1(-1.3-1.8)$. All measurements were successful and were performed within the allotted time. None of the measurements was excluded from further analysis.

The reproducibility data according to the Bland-Altman analysis, SDC and intra- and inter-observer ICCs are shown in Table 1. Bland-Altman plots for all parameters are shown in Figs. 1 and 2. No systematic difference was found between the pairs of measurements by the same rater.

\section{Reference values}

A total of 2119 children and adolescents were included into the study, of whom ten were excluded due to a failed measurement, three children refused the BCM measurement, three children were excluded for comorbidities (chronic diseases) and 45 were excluded for not fulfilling the inclusion criteria: 22 children were younger than 3 years and 23 adolescents were older than 18 years. In total, 2058 subjects were included for further analysis, with a mean age of $11 \pm 4$ years and $51 \%$ of the population was male. The average weight was $40.9 \pm$ $18.8 \mathrm{~kg}$ and the average height was $145.2 \pm 24.9 \mathrm{~cm}$, which corresponds with an average BMI of $18.2 \pm 3.5 \mathrm{~kg} / \mathrm{m}^{2}$ and BMI SDS of $-0.05 \pm 0.95$.

A wide range of BMI SDS was apparent across all age ranges, as is shown in Supplemental Fig. S1.

Supplemental Tables S1-S4 show the gender- and agespecific percentile values for BMI, waist circumference, FM and LTM at the 3th, 5th, 10th, 25th, 75th, 90th, 95th and 97th
Table 1 Reproducibility in terms of intraclass correlation coefficients, Bland-Altman analysis and smallest detectable change

\begin{tabular}{|c|c|c|c|c|c|c|}
\hline & \multicolumn{2}{|l|}{ ICC } & \multicolumn{3}{|c|}{ Bland-Altman analysis } & \multirow[t]{3}{*}{ SDC } \\
\hline & \multirow[b]{2}{*}{$\begin{array}{l}\text { Intra- } \\
\text { observer }\end{array}$} & \multirow[b]{2}{*}{$\begin{array}{l}\text { Inter- } \\
\text { observer }\end{array}$} & \multicolumn{2}{|l|}{ Intra-rater } & \multirow{2}{*}{$\begin{array}{l}\text { Inter-rater } \\
\text { LoA }\end{array}$} & \\
\hline & & & Mean difference & LoA & & \\
\hline FAT (kg) & 0.99 & 0.98 & 0.02 & $-0.89-0.93$ & $-1.10-1.10$ & 0.92 \\
\hline LTM $(\mathrm{kg})$ & 0.99 & 0.99 & -0.02 & $-1.34-1.30$ & $-1.70-1.70$ & 1.34 \\
\hline TBW (litres) & 0.99 & 0.99 & -0.02 & $-0.60-0.56$ & $-0.81-0.81$ & 0.58 \\
\hline ECW (litres) & 0.99 & 0.99 & -0.01 & $-0.19-0.17$ & $-0.20-0.20$ & 0.17 \\
\hline $\mathrm{OH}$ (litres) & 0.97 & 0.76 & 0.006 & $-0.21-0.22$ & $-0.41-0.41$ & 0.23 \\
\hline
\end{tabular}

ICCs intraclass correlation coefficients, $L O A$ limits of agreement, SDC smallest detectable change, LTM lean tissue mass, $T B W$ total body water, $E C W$ extracellular water, $O H$ overhydration 

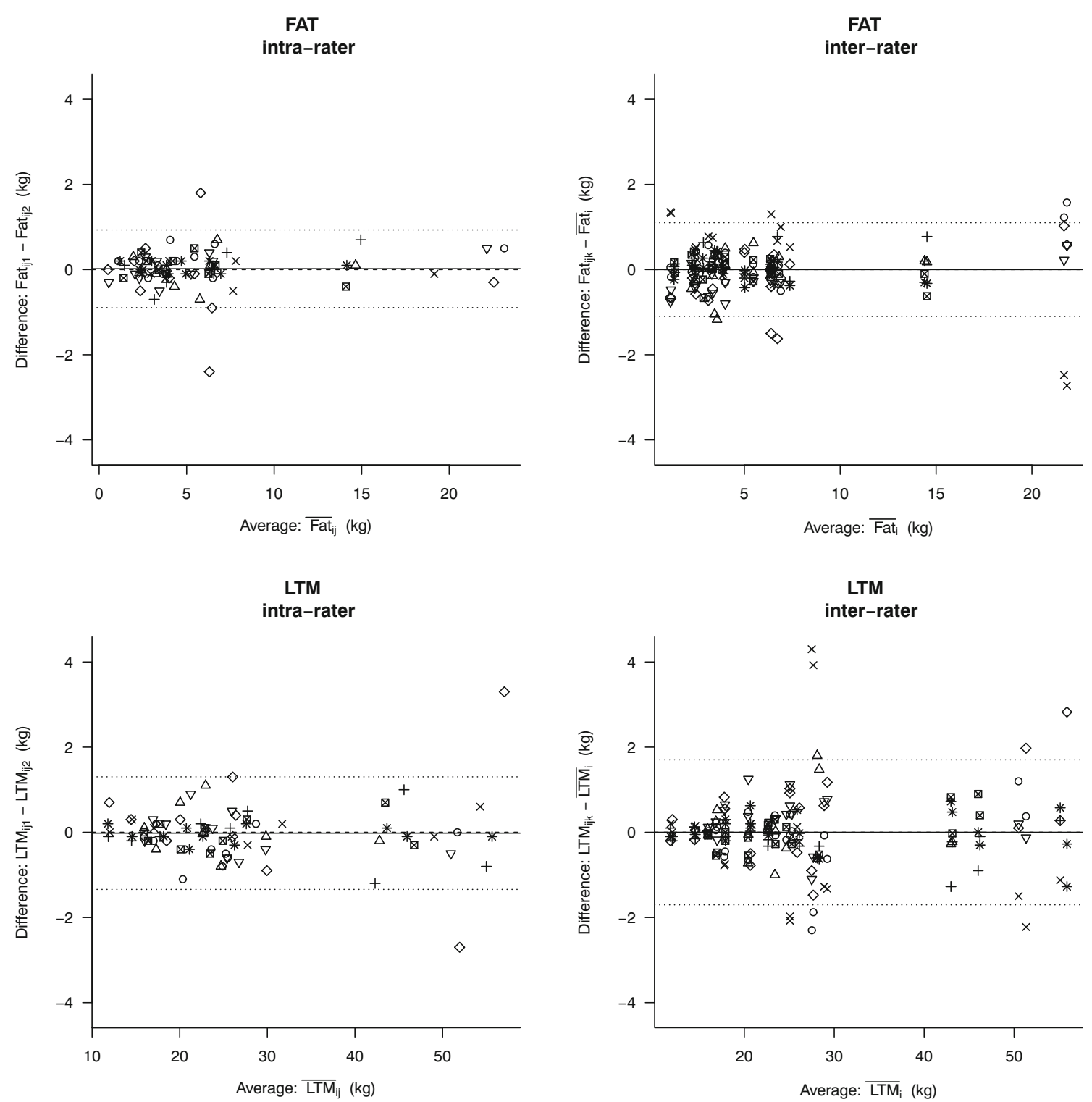

Fig. 1 Bland-Altman plots for fat mass (FAT) and lean tissue mass (LTM). The left panels show classical Bland-Altman plots for intrarater reproducibility with two repeated measures per child-rater combination. The right panels show modified Bland-Altman plots for

percentiles. Figure 3 shows the corresponding reference curves. BMI, waist circumference, FM and LTM increased with age in both genders.

At the 50th percentile, the FM for boys is $2.48 \mathrm{~kg}$ at 3 years and increases to $9.22 \mathrm{~kg}$ at 18 years, while for girls, the FM starts at $2.39 \mathrm{~kg}$ but increases to a median of $17.06 \mathrm{~kg}$ at the age of 18 years. The opposite can be seen in LTM, with a higher median increase with age in boys compared to girls (11.84 kg to $56.96 \mathrm{~kg}$ vs. 11.14 to $37.50 \mathrm{~kg}$ at 18 years, respectively). This gender difference extrapolates to all percentiles (Supplemental Table). In contrast, BMI did not show this discrepancy, as the median BMI for boys is $16.02 \mathrm{~kg} / \mathrm{m}^{2}$ at 3 years and increases to $21.50 \mathrm{~kg} / \mathrm{m}^{2}$ at 18 years, while the inter-rater reproducibility with 4 raters. Each rater is depicted by a different symbol. The mean of the within-person differences and upper and lower limits of agreement are depicted by the horizontal lines

median BMI for girls starts at $15.63 \mathrm{~kg} / \mathrm{m}^{2}$ and increases to $21.97 \mathrm{~kg} / \mathrm{m}^{2}$ at 18 years.

Gender- and age-specific percentile values for ECW, ICW and TBW at the 3th, 5th, 10th, 25th, 75th, 90th, 95th and 97th percentiles are shown in Supplemental Tables S5-S7 with the corresponding reference curves in Fig. 4. ECW, ICW and TBW all increased with age in both genders; however, this increase was more pronounced in boys compared to girls for all parameters.

The precision of the percentile curves, as computed by bootstrap simulations, is between 10 and $15 \%$ of the agedependent standard deviation in the middle range of the ages and $30 \%$ in the boundaries of the sample. 
Fig. 2 Bland-Altman plots for overhydration $(\mathrm{OH})$, total body water (TBW) and extracellular water $(\mathrm{ECW})$. The left panels show classical Bland-Altman plots for intra-rater reproducibility with two repeated measures per child-rater combination. The right panels show modified BlandAltman plots for inter-rater reproducibility with 4 raters. Each rater is depicted by a different symbol. The mean of the withinperson differences and upper and lower limits of agreement are depicted by the horizontal lines

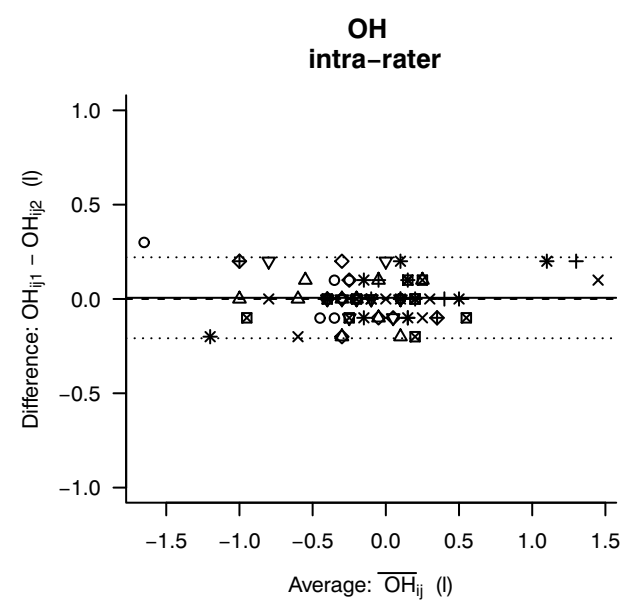

TBW

intra-rater

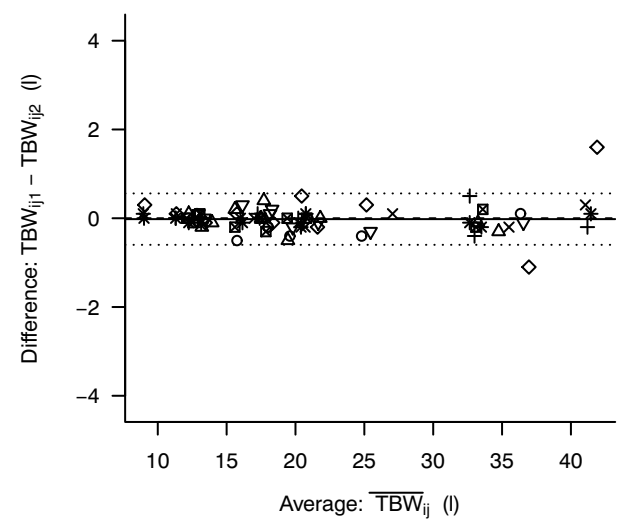

ECW

intra-rater

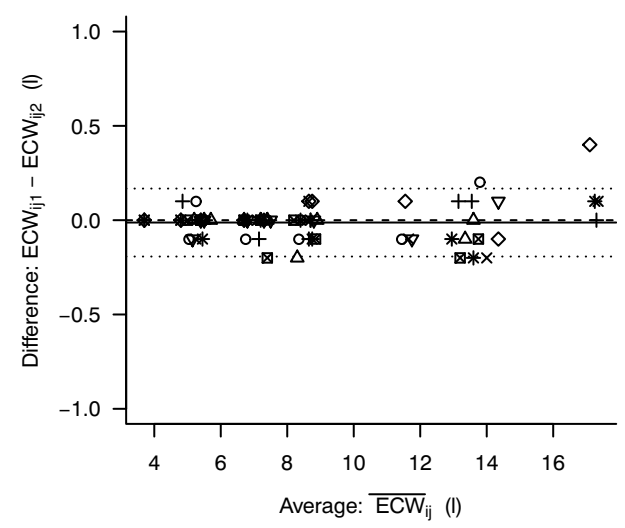

$\mathrm{OH}$

inter-rater

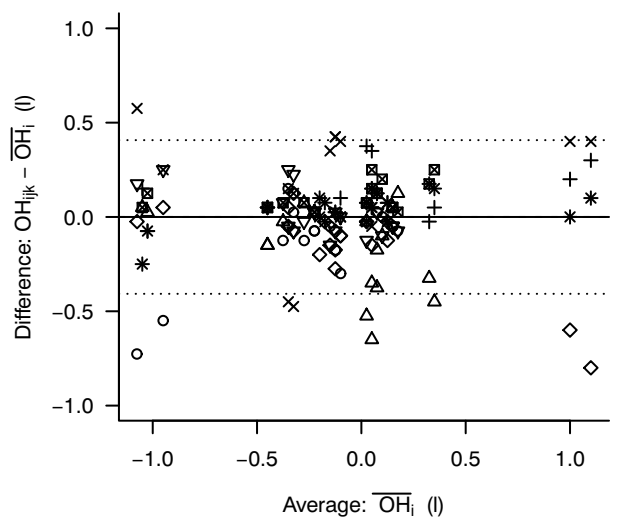

TBW

inter-rater

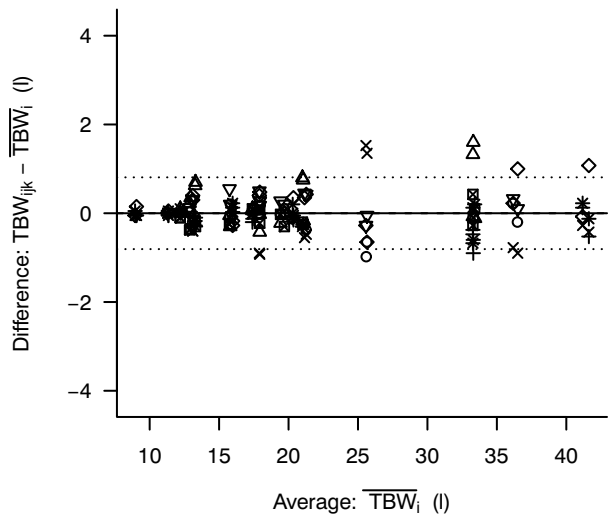

ECW

inter-rater

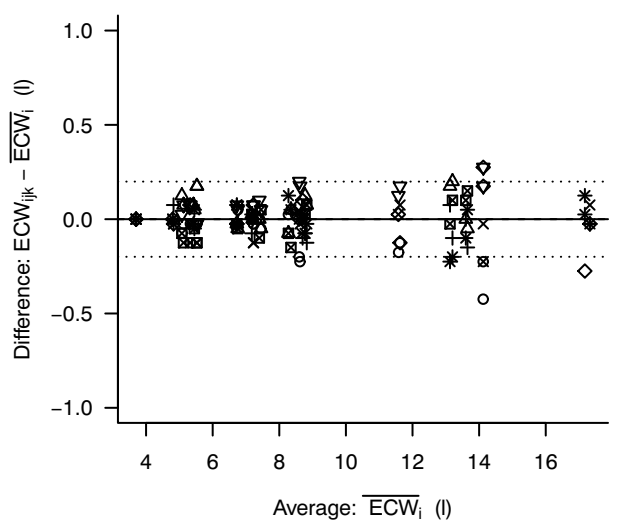

\section{Discussion}

Body composition measurements are gaining interest in the scientific scene of chronic diseases [24-26] as well as childhood obesity [27, 28]. Reliable tools for measuring the various compartments of the body are therefore essential in order to perform research in a standardized manner in the most optimal circumstances. Besides, reference values for each body compartment are needed to draw the right conclusions when measuring the body composition in children and adolescents who suffer from obesity or other chronic diseases. In the first part of this manuscript, the reproducibility and reliability of $\mathrm{BCM}$ measurements were demonstrated. In the second part, reference curves for BCM were plotted in over 2000 Belgian children aged 3 to 18 years. 

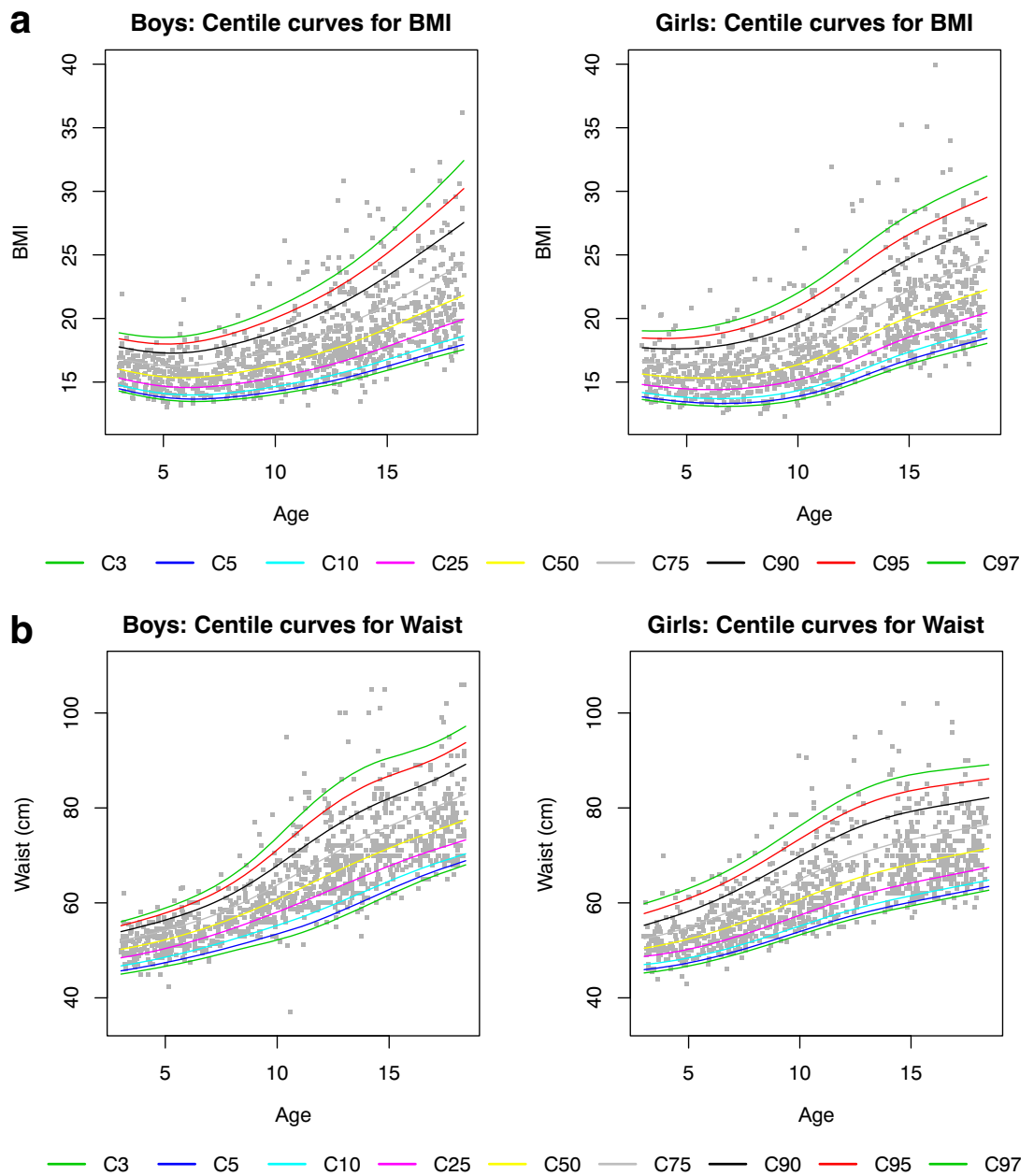

Fig. 3 Percentile graphs for age in boys (left panels) and girls (right panels) aged 3 to 18 years. a Body mass index (BMI), b waist, $\mathbf{c}$ fat mass (FAT) and d lean tissue mass (LTM)

Bioimpedance analysis (BIA) such as BCM® type BISBIA by Fresenius is a relatively simple, quick and noninvasive technique that is easy to use when performing field studies involving children [29]. The intra- and inter-rater reliability of BCM was obtained in twenty children who were each measured twice by four different raters. The applicability of the Fresenius device in clinical studies was confirmed with exclusively successful measurements without the necessity for any repeated measurements. In this study, a high intra- and inter-rater reproducibility of the $\mathrm{BCM}$ measurements in healthy children aged 3 to 18 years (ICC $\geq 0.98$ ) was observed for fat mass, lean tissue mass, extracellular water and total body water, making the Fresenius BCM a reliable tool for the monitoring of individual prospective changes in hydration status, fat mass and lean tissue mass in longitudinal studies. Besides, since the observer-dependent bias remained low, we provide evidence that the BCM device is indeed useful for multicentre and comparative studies. However, as can be noticed in the Bland-Altman figures, there are some divergent measurements for each body compartment without any reasonable explanation. The same $\mathrm{BCM}$ device and investigation room were used by the co-raters, and the quality of each measurement was rated at more than $75 \%$.

For 'overhydration', the intra-rater agreement between measurements was high (ICC 0.97); however, the inter-rater reproducibility did not perform so well (ICC 0.76 ). 'Overhydration' should be disregarded in healthy children [10] as it might depend on fluid intake and physical activity. The children included into this study were measured by four different raters. Each rater performed two measurements in the same child within $30 \mathrm{~min}$. Given this short time between measurements, no influence of fluid intake was expected in the child and the intra-rater agreement performed well. However, there was a longer period between the measurements of the different observes ( 1 to $4 \mathrm{~h}$ ) and the children had free access to fluids during the entire study protocol, potentially explaining the higher inter-rater variability for overhydration. Therefore, the relatively low inter-rater reproducibility is considered an artefact as a result of a design flaw.

Based on the reproducibility data, reference values in children and adolescents were calculated for each separate body compartment, except for 'overhydration'. First, anthropology 


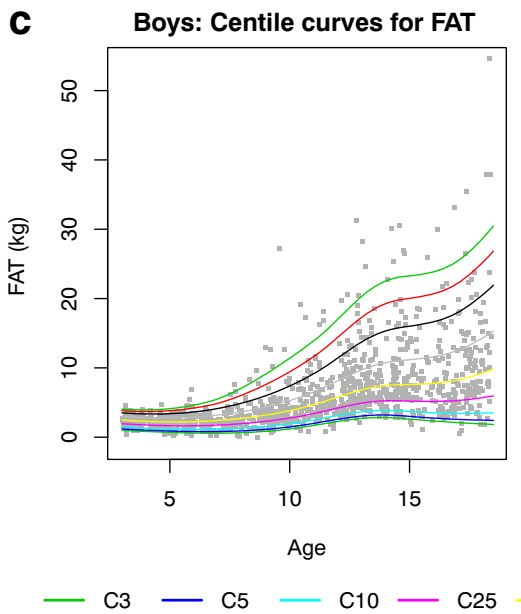

d

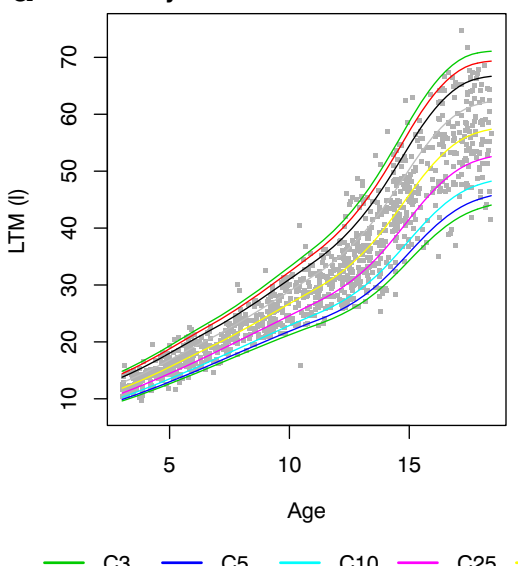

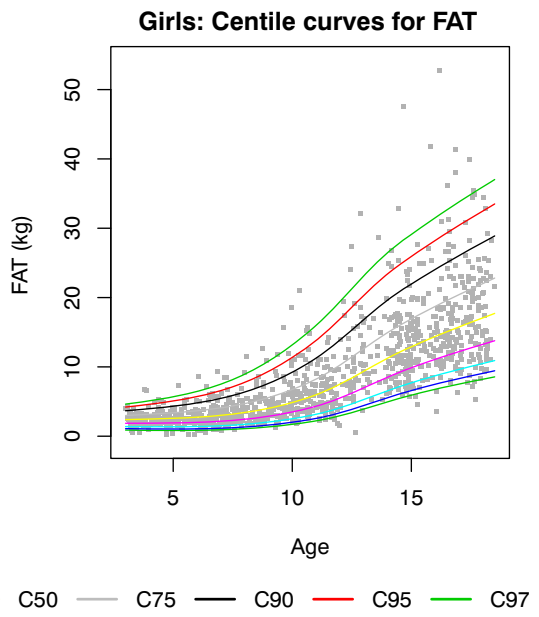

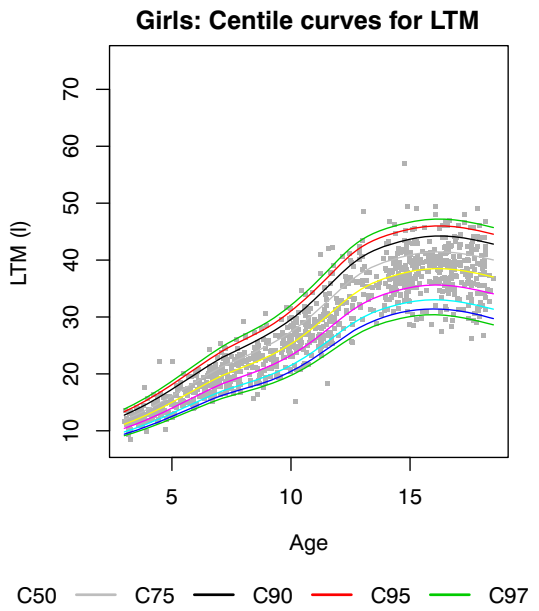

Fig. 3 continued.

was verified with the measurements of weight, length, BMI (and BMI SDS) and waist circumference. BMI corrected for age and sex is still considered a proxy of adiposity in children and adolescents [30]. However, BMI does not distinguish between fat mass and lean tissue mass and does thus not accurately reflect the body composition [31]. In the present population, BMI z-scores were similar to the reference values described by Roelants et al [13]. The children and adolescents included in the present study thus represent the overall population. In contrast to BMI, waist circumference is a better estimate of trunk fat mass in children and adolescents [32]. In comparison with the reference values in $580 \mathrm{New}$ Zealand children and adolescents [32], in 22,000 Brazilian children aged 6 to 10 years [33] and in Tunisian children [34], the waist circumference was slightly lower in each age category in our population, confirming the need for reference values at a regional level. The waist circumference values of the children aged 3 to 10 years are highly comparable to the European values published by Nagy et al. in 2014 [31]. In our population, in addition to the 3- to 10-year-old children, also reference values are calculated for children aged 10 to 18 years and might thus serve as reference values in a European population.
Second, BCM measurements were performed. To date, BCM is mostly applied to estimate the body fluid overload in dialysis patients [10]. For this purpose, the device is well validated in adults and children [10,35]. However, reference values for fat mass and lean tissue mass in children and adolescents are lacking. In the present study, over 2000 children and adolescents were included in 16 elementary and high schools spread over Flanders and Brussels. With the increasing interest in body composition studies in obesity and chronic diseases, the results described in this manuscript might serve as reference values for future studies on this topic.

Fat mass or adipose tissue is a major storage for energy and besides actively secretes metabolically active adipokines involved in among others inflammatory processes [36]. An accurate measurement of the fat mass is thus essential in research projects investigating the adipose tissue in health and disease. In children and adolescents with intentional (overweight, obesity) or unintentional weight loss (acute or chronic diseases), it is of utmost interest to make a distinction between a reduction in fat mass or in a reduction in muscle mass (protein-energy wasting syndrome). Since the BMI is not able to discriminate fat mass from lean tissue mass, the $\mathrm{BCM}$ is a superior 
Fig. 4 Percentile graphs for age in boys (left panels) and girls (right panels) aged 3 to 18 years. a Extracellular water (ECW), b intracellular water (ICW) and $\mathbf{c}$ total body water
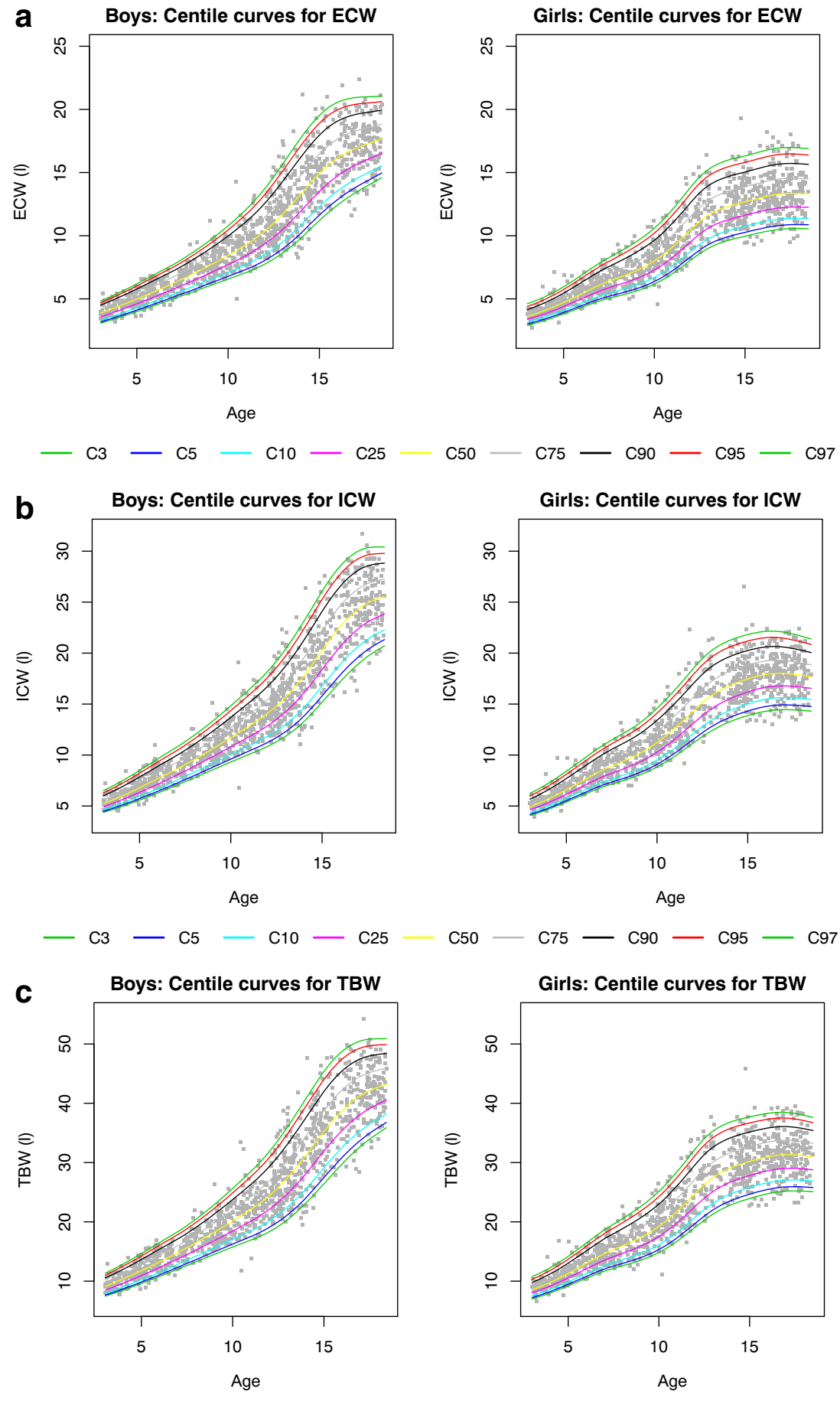

$-\mathrm{C} 3-\mathrm{C} 5-\mathrm{C} 10-\mathrm{C} 25$ alternative by differentiating both fat mass and lean tissue mass. Our main goal was to provide reference values for fat mass and lean tissue mass measured by the Fresenius BCM device. In this study, the association of fat mass with age was less steep in boys than in girls. At the age of 18 years, the median fat mass was 1.85 times higher in girls compared to boys. The opposite was seen in lean tissue mass, with a higher median increase with age in boys compared to girls. This gender difference extrapolates to all percentiles. When compared to the reference study of Nagy et al [31], where fat mass was calculated based on skin folds, the difference in median fat mass between boys and girls at the age of 10 years was comparable to our results (factor 1.22 and 1.27, respectively). In a British population, the difference between boys and girls 
was more pronounced at the age of 10 years (factor 1.5 in girls compared to boys), while this difference was less visible at the age of 18 years (factor 1.5 in the British population) [37].

In this paper, reference values for extracellular water and total body water are provided as well. The generalizability of total body water measured by the Fresenius BCM device was validated in children and adolescents in the Dasgupta study [10]. Extracellular water, intracellular water and total body water all increased with age in both genders; however, this increase was more pronounced in boys compared to girls for all parameters. Food and drink intake of the children was not monitored in this study. However, according to Wabel et al. [38], food intake does not influence the reliability of the device. Since overhydration is supposed to be absent in healthy children, no reference values for this parameter were calculated. From the statistical analysis, however, it was clear that overhydration was not age dependent (data not shown).

The major strength of this study was the combination of reproducibility of the $\mathrm{BCM}$ results on the one hand and the inclusion of over 2000 patients with age range between 3 and 18 years on the other hand, resulting in reliable reference values. The data published in this manuscript therefore serve as a solid reference base for future multicentre or longitudinal studies investigating body composition in children and adolescents.

Unfortunately, we were not able to include children younger than 3 years and reference body composition values in this very young population remain therefore unexplored. Furthermore, it should be kept in mind that BIS is not a direct measurement of the body compartments but only of the electrical properties of tissues that are used for the calculation of body composition [39]. A volume model based on the Hanai mixture theory is used to determine TBW, ECW and ICW [35]. Overhydration, LTM and adipose tissue are then calculated by a body composition algorithm from the ECW and TBW information [8].

In conclusion, this paper provides evidence for the reproducibility and reliability of BCM measurements with excellent intra- and inter-rater reproducibility for fat mass, lean tissue mass, extracellular water and total body water. Reference values for these BCM parameters were calculated in over 2000 Belgian children and adolescents aged 3 to 18 years.

Supplementary Information The online version contains supplementary material available at https://doi.org/10.1007/s00431-021-03936-0.

Acknowledgements Special thanks to all colleagues who performed the $\mathrm{BCM}$ measurements for the inter- and intra-rater reproducibility and for the calculation of reference values. We also thank all volunteers who joined our research team and made a fluid study protocol possible. Finally, we also like to thank the participating schools (Damiaaninstituut Aarschot, Koninklijk Lyceum Antwerpen, Onze-Lieve-Vrouwecollege Antwerpen, Sint-Jozef Schoten, Sint-Michielscollege Brasschaat, Sint-Jan
Berchmanscollege Brussel, Sint-Jozefsinstituut Borsbeek, Sint-Ursulainstituut Lier, Sint-Ursula Lyceum Lier, OLV Ten Bos Nieuwkerken, Sint Jozef Reet, Rozenkransschool Wilrijk, Sint-Jozef-Klein-Seminarie Sint Niklaas, De Droomwolk Kieldrecht, Kleuterschool Ter Leie - De Bollekens Gent), the time spent for the children's recruitment, the organization on-site and for welcoming our research team.

Authors' contributions All authors certify that they have participated in the study and take responsibility for the content. Annelies Van Eyck: study design, measurements, data collection, data interpretation and preparation of the manuscript, critical revision of the manuscript. Sofie Eerens: measurements, data collection, data interpretation, preparation of the manuscript. Dominique Trouet: study design, data interpretation and critical revision of the manuscript. Eline Lauwers: measurements, preparation of the manuscript. Kristien Wouters: statistical analysis Benedicte Y. De Winter: study design and critical revision of the manuscript. Johanna H. van der Lee: statistical analysis Koen Van Hoeck: study design, data interpretation and preparation of the manuscript. Kristien J. Ledeganck: study design, measurements, data collection, data interpretation, preparation of the manuscript, critical revision of the manuscript.

Funding An unrestricted grant was obtained from Fresenius Medical Care. Fresenius Medical Care did not influence the study design nor the data collection, analysis, interpretation or writing of the manuscript. They had no participation in the writing or submission of the manuscript. The researchers are independent of the financial sponsor. All authors had full access to the study data and take responsibility for the accuracy and the integrity of the data and the data analysis.

\section{Compliance with ethical standards}

Disclaimer Fresenius Medical Care delivered multiple BCM devices that were used for the measurements during this project. Electrodes and memory cards were provided by Fresenius Medical Care for the measurements of inter- and intra-rater variability and the measurements in the secondary and preschools.

Conflict of interest The authors declare that they have no conflict of interest.

Ethics approval This study was performed in line with the principles of the Declaration of Helsinki. Approval was granted by the Ethics Committee of the Antwerp University Hospital (No. n B300201939802 and B300201214619).

Consent to participate Written informed consent was obtained from all individual participants and their parents or legal guardians.

\section{Consent for publication N/A}

Data availability N/A

Code availability N/A

Open Access This article is licensed under a Creative Commons Attribution 4.0 International License, which permits use, sharing, adaptation, distribution and reproduction in any medium or format, as long as you give appropriate credit to the original author(s) and the source, provide a link to the Creative Commons licence, and indicate if changes were made. The images or other third party material in this article are included in the article's Creative Commons licence, unless indicated otherwise in a credit line to the material. If material is not included in the 
article's Creative Commons licence and your intended use is not permitted by statutory regulation or exceeds the permitted use, you will need to obtain permission directly from the copyright holder. To view a copy of this licence, visit http://creativecommons.org/licenses/by/4.0/.

\section{References}

1. WHO (2017) Childhood overweight and obesity. http://www.who. int/dietphysicalactivity/childhood/en/. Accessed July 12020

2. Orsso CE, Silva MIB, Gonzalez MC, Rubin DA, Heymsfield SB, Prado CM, Haqq AM (2020) Assessment of body composition in pediatric overweight and obesity: a systematic review of the reliability and validity of common techniques. Obes Rev 21(8): e13041. https://doi.org/10.1111/obr.13041

3. Weber DR, Leonard MB, Zemel BS (2012) Body composition analysis in the pediatric population. Pediatr Endocrinol Rev 10(1): 130-139

4. Daniels SR, Khoury PR, Morrison JA (1997) The utility of body mass index as a measure of body fatness in children and adolescents: differences by race and gender. Pediatrics 99(6):804-807. https://doi.org/10.1542/peds.99.6.804

5. Silva AM, Fields DA, Sardinha LB (2013) A PRISMA-driven systematic review of predictive equations for assessing fat and fat-free mass in healthy children and adolescents using multicomponent molecular models as the reference method. J Obes 2013:148696148614. https://doi.org/10.1155/2013/148696

6. Smith-Ryan AE, Mock MG, Ryan ED, Gerstner GR, Trexler ET, Hirsch KR (2017) Validity and reliability of a 4-compartment body composition model using dual energy $\mathrm{x}$-ray absorptiometry-derived body volume. Clin Nutr 36(3):825-830. https://doi.org/10.1016/j. clnu.2016.05.006

7. Johnson AJ, Matthie JR, Kuchnia A, Teigen LM, Beckman LM, Mager JR, Nicklay SA, Mulasi U, Sibley SD, Nagel E, Earthman CP (2017) Evaluation of advanced bioimpedance spectroscopy models for measuring body composition in healthy adults (NHANES 1999-2004) and those undergoing massive weight loss following roux-en-Y gastric bypass surgery. BRASPEN J 32(3): 193-202

8. Chamney PW, Wabel P, Moissl UM, Muller MJ, Bosy-Westphal A, Korth O, Fuller NJ (2007) A whole-body model to distinguish excess fluid from the hydration of major body tissues. Am J Clin Nutr 85(1):80-89. https://doi.org/10.1093/ajcn/85.1.80

9. Wabel P, Chamney P, Moissl U, Jirka T (2009) Importance of whole-body bioimpedance spectroscopy for the management of fluid balance. Blood Purif 27(1):75-80. https://doi.org/10.1159/ 000167013

10. Dasgupta I, Keane D, Lindley E, Shaheen I, Tyerman K, Schaefer F, Wuhl E, Muller MJ, Bosy-Westphal A, Fors H, Dahlgren J, Chamney P, Wabel P, Moissl U (2018) Validating the use of bioimpedance spectroscopy for assessment of fluid status in children. Pediatr Nephrol 33(9):1601-1607. https://doi.org/10.1007/ s00467-018-3971-x

11. Broers NJH, Canaud B, Dekker MJE, van der Sande FM, Stuard S, Wabel P, Kooman JP (2020) Three compartment bioimpedance spectroscopy in the nutritional assessment and the outcome of patients with advanced or end stage kidney disease: what have we learned so far? Hemodial Int 24(2):148-161. https://doi.org/10. 1111/hdi.12812

12. Vermeiren E, Ysebaert M, Van Hoorenbeeck K, Bruyndonckx L, Van Dessel K, Van Helvoirt M, De Guchtenaere A, De Winter B, Verhulst S, Van Eyck A (2020) Comparison of bioimpedance spectroscopy and dual energy X-ray absorptiometry for assessing body composition changes in obese children during weight loss. Eur J Clin Nutr. https://doi.org/10.1038/s41430-020-00738-9

13. Roelants M, Hauspie R, Hoppenbrouwers K (2009) References for growth and pubertal development from birth to 21 years in Flanders, Belgium. Ann Hum Biol 36(6):680-694. https://doi.org/ $10.3109 / 03014460903049074$

14. Shrout PE, Fleiss JL (1979) Intraclass correlations: uses in assessing rater reliability. Psychol Bull 86(2):420-428. https://doi.org/10. 1037//0033-2909.86.2.420

15. Streiner D, Norman G (2003) Health measurement scales: a practical guide to their development and use. Oxford University Press, Oxford

16. Terwee CB, Bot SD, de Boer MR, van der Windt DA, Knol DL, Dekker J, Bouter LM, de Vet HC (2007) Quality criteria were proposed for measurement properties of health status questionnaires. J Clin Epidemiol 60(1):34-42. https://doi.org/10.1016/j. jclinepi.2006.03.012

17. Bland JM, Altman DG (1986) Statistical methods for assessing agreement between two methods of clinical measurement. Lancet 1(8476):307-310

18. Jones M, Dobson A, O'Brian S (2011) A graphical method for assessing agreement with the mean between multiple observers using continuous measures. Int J Epidemiol 40(5):1308-1313. https://doi.org/10.1093/ije/dyr109

19. Bonett DG (2002) Sample size requirements for estimating intraclass correlations with desired precision. Stat Med 21(9): 1331-1335. https://doi.org/10.1002/sim.1108

20. Rigby RA, Stasinopoulos DM (2005) Generalized additive models for location, scale and shape. J R Stat Soc C-Appl 54:507-544. https://doi.org/10.1111/j.1467-9876.2005.00510.x

21. Cole TJ, Green PJ (1992) Smoothing reference centile curves - the LMS method and penalized likelihood. Stat Med 11(10):13051319. https://doi.org/10.1002/sim.4780111005

22. Rigby RA, Stasinopoulos DM (2007) Generalized additive models for location scale and shape (GAMLSS) in R. J Stat Softw 23(7):1-46

23. Cole TJ (2020) Sample size and sample composition for constructing growth reference centiles. Stat Methods Med Res: 962280220958438. https://doi.org/10.1177/0962280220958438

24. Karava V, Printza N, Dotis J, Demertzi D, Antza C, Kotsis V, Papachristou F, Stabouli S (2019) Body composition and arterial stiffness in pediatric patients with chronic kidney disease. Pediatr Nephrol 34(7):1253-1260. https://doi.org/10.1007/s00467-01904224-8

25. Gallagher D, Andres A, Fields DA, Evans WJ, Kuczmarski R, Lowe WL Jr, Lumeng JC, Oken E, Shepherd JA, Sun S, Heymsfield SB (2020) Body composition measurements from birth through 5 years: challenges, gaps, and existing \& emerging technologies-a National Institutes of Health workshop. Obes Rev 21(8):e13033. https://doi.org/10.1111/obr.13033

26. Wiech P, Salacinska I, Bazalinski D, Dabrowski M (2018) Body composition and phase angle as an indicator of nutritional status in children with juvenile idiopathic arthritis. Pediatr Rheumatol Online J 16(1):82. https://doi.org/10.1186/s12969-018-0297-y

27. Thajer A, Truschner K, Jorda A, Skacel G, Horsak B, GreberPlatzer S (2020) A strength and neuromuscular exercise program did not improve body composition, nutrition and psychological status in children with obesity. Acta Paediatr 110:288-289. https://doi.org/10.1111/apa.15498

28. Lee S, Libman I, Hughan KS, Kuk JL, Barinas-Mitchell E, Chung H, Arslanian S (2020) Effects of exercise modality on body composition and cardiovascular disease risk factors in adolescents with obesity: a randomized clinical trial. Appl Physiol Nutr Metab 45: 1377-1386. https://doi.org/10.1139/apnm-2019-0993

29. Wang L, Hui SS (2015) Validity of four commercial bioelectrical impedance scales in measuring body fat among Chinese children 
and adolescents. Biomed Res Int 2015:614858-614858. https://doi. org/10.1155/2015/614858

30. Kigaru DMD, Ndung'u ZW, Macharia-Mutie CW (2020) Application of stable isotope dilution techniques to assess body fat and comparison with WHO BMI-for-age classification as a measure of obesity among schoolchildren in Nairobi, Kenya. Public Health Nutr 1-5. https://doi.org/10.1017/S1368980020001950

31. Nagy P, Kovacs E, Moreno LA, Veidebaum T, Tornaritis M, Kourides Y, Siani A, Lauria F, Sioen I, Claessens M, Marild S, Lissner L, Bammann K, Intemann T, Buck C, Pigeot I, Ahrens W, Molnar D, consortium I (2014) Percentile reference values for anthropometric body composition indices in European children from the IDEFICS study. Int J Obes 38(Suppl 2):S15-S25. https://doi. org/10.1038/ijo.2014.131

32. Taylor RW, Jones IE, Williams SM, Goulding A (2000) Evaluation of waist circumference, waist-to-hip ratio, and the conicity index as screening tools for high trunk fat mass, as measured by dual-energy X-ray absorptiometry, in children aged 3-19 y. Am J Clin Nutr 72(2):490-495. https://doi.org/10.1093/ajen/72.2.490

33. Santos JLF, Valerio VP, Fernandes RN, Duarte L, Assumpcao AC, Guerreiro J, Sickler AL, Lemos AAR, Goulart Filho JG, Cesar LAM, Pinto IM, Magalhaes C, Hussid MF, Camacho C, Avezum A, Sangaleti CT, Consolim-Colombo FM (2020) Waist circumference percentiles and cut-off values for obesity in a large sample of students from 6 to 10 years old of the Sao Paulo State, Brazil. Arq Bras Cardiol 114(3):530-537. https://doi.org/10.36660/abc. 20190043

34. Ghouili H, Ouerghi N, Ben Khalifa W, Boughalmi A, Dridi A, Gmada N, Bouassida A (2020) First reference curves of waist circumference and waist-to-height ratio for Tunisian children. Arch Pediatr 27(2):87-94. https://doi.org/10.1016/j.arcped.2019. 11.009

35. Moissl UM, Wabel P, Chamney PW, Bosaeus I, Levin NW, BosyWestphal A, Korth O, Muller MJ, Ellegard L, Malmros V, Kaitwatcharachai C, Kuhlmann MK, Zhu F, Fuller NJ (2006) Body fluid volume determination via body composition spectroscopy in health and disease. Physiol Meas 27(9):921-933. https:// doi.org/10.1088/0967-3334/27/9/012

36. Mafra D, Guebre-Egziabher F, Fouque D (2008) Body mass index, muscle and fat in chronic kidney disease: questions about survival. Nephrol Dial Transplant 23(8):2461-2466. https://doi.org/10.1093/ $\mathrm{ndt} / \mathrm{gfn} 053$

37. Wells JC, Williams JE, Chomtho S, Darch T, Grijalva-Eternod C, Kennedy K, Haroun D, Wilson C, Cole TJ, Fewtrell MS (2012) Body-composition reference data for simple and reference techniques and a 4-component model: a new UK reference child. Am J Clin Nutr 96(6):1316-1326. https://doi.org/10.3945/ajen.112. 036970

38. Wabel P, Chamney P, Moissl U, Schultheiss B, Rode C, Wieskotten S, Wizemann V, Charra B (2007) Reproducibility of bioimpedance spectroscopy (BIS) in health and disease. Nephrol Dial Transplant 22:137-137

39. Ward LC (2019) Bioelectrical impedance analysis for body composition assessment: reflections on accuracy, clinical utility, and standardisation. Eur J Clin Nutr 73(2):194-199. https://doi.org/10. 1038/s41430-018-0335-3

\section{Affiliations}

\section{Annelies Van Eyck ${ }^{1,2} \cdot$ Sofie Eerens ${ }^{2} \cdot$ Dominique Trouet $^{1,2} \cdot$ Eline Lauwers $^{1} \cdot$ Kristien Wouters $^{3,4} \cdot$ Benedicte Y. De $^{2}$ Winter $^{1,5}$ • Johanna H. van der Lee ${ }^{6}$ - Koen Van Hoeck ${ }^{2}$ - Kristien J. Ledeganck ${ }^{1,7}$}

1 Laboratory of Experimental Medicine and Pediatrics and member of the Infla-Med Centre of Excellence, University of Antwerp, Wilrijk, Belgium

2 Department of Pediatrics, Antwerp University Hospital, Edegem, Belgium

3 Clinical Trial Center (CTC), CRC Antwerp, Antwerp University Hospital, Edegem, Belgium

4 Faculty of Medicine and Health Sciences, University of Antwerp, Antwerp, Belgium
5 Department of Gastroenterology and Hepatology, Antwerp University Hospital, Edegem, Belgium

6 Emma Children's Hospital, Amsterdam UMC, University of Amsterdam, Pediatric Clinical Research Office, AMC, Amsterdam, The Netherlands

7 University of Antwerp, Universiteitsplein 1, T3.34, 2610 Antwerp, Belgium 